www.jmscr.igmpublication.org

Index Copernicus Value: 79.54

ISSN (e)-2347-176x ISSN (p) 2455-0450

crossref DOI: https://dx.doi.org/10.18535/jmscr/v7i5.33

Journal Of Medical Science And Clinical Research

IGM Publication

An Official Publication of IGM Publication

\title{
Surgical closure of VSD in infants: Results in our centre over 4 years
}

Authors

Dr Mohd Javed Banday, Dr Dhananjay Bansal, Dr Rahul Bhushan, Dr Narender Singh Jhajhria*, Dr Vijay Grover, Dr Vijay Gupta

PGIMER, Dr R.M.L. hospital, New Delhi, New Delhi, Pin Code: 110001

Email: javedbanday82@gmail.com

*Corresponding Author

Dr Narender Singh Jhajhria

Prof Dept of CTVS, Dr RML Hospital, New Delhi, India

Telephone: 01123404562, Fax: 0112374788, Email: drnsjhajhria@yahoo.com

\begin{abstract}
Ventricular septal defect (VSD) is the most commonly diagnosed congenital heart defect presenting with failure to thrive. Surgical closure of the defect is the treatment of choice for these patients and should be done preferably in infancy. We present our experience of 84 patients of isolated VSD below one year of age treated in our hospital over period of four years. The median age of patient was 8 months (range 2 months to 11.5 months) and a median weight of $5 \mathrm{~kg}$ (range $2.5 \mathrm{~kg}$ to $9 \mathrm{~kg}$ ). The following VSD types were found: 74 perimembranous (88\%), 2 supracristal (2.3\%), 3 inlet (3.5\%) and 5 muscular (5.9\%). Most common indication was recurrent pneumonias and failure to thrive. Pulmonary artery hypertension was present in 55 patients $(65 \%)$ out of 84 .

None of our patient was re-operated for residual VSD. Median extubation time was 12 hours (range 6 hours to 30 hours), median ICU stay was 3 days (range 2 to 15 days) and median hospital length of stay was 5 days (range 4 to 26 days). There were 2 early mortalities (2.3\%) and 1 late death (1.15\%) in our series. 1 patient developed complete heart block requiring permanent pacemaker implant. 50 patients were discharged on medication for pulmonary hypertension. Pulmonary hypertension regressed over median time of 2 months. On median follow up of 2 years, 80 patients (95\%) were asymptomatic. No patient had new onset aortic or tricuspid regurgitation greater than trivial postoperatively.

We concluded early surgical closure of VSD in infancy is treatment of choice for patients with VSD with low mortality and extremely low incidence of adverse events.
\end{abstract}

\section{Introduction}

Ventricular septal defect (VSD) is the most commonly diagnosed congenital heart defect, occurring in approximately 2 of 1,000 live births, and one of the most common congenital cardiac lesion requiring surgical intervention ${ }^{1}$. Surgical closure of VSD was first performed in 1955 by
Lillehei and associates, and since then improvements in surgical techniques as well as advancements in techniques of cardiopulmonary bypass, myocardial preservation, anesthesia, and postoperative care, have greatly reduced operative mortality and morbidity ${ }^{2}$. 
Anderson et al. found that young age ( $\geq 6$ months) and low body weight were risk factors for complications $^{3}$. This, however, contrasts with data published by Kogon et al. and many others in recent series ${ }^{4}$. The purpose of this study is to evaluate the results of surgical VSD closure in infants less than one year and to define whether infancy is a risk factors for VSD closure or not.

\section{Patients and Methods}

\section{Patient Population}

Database of all patients with age less than one year, who were operated in our hospital between January 1, 2014 and December 31, 2017 was collected.

\section{Inclusion Criterion}

1) Children of less than one year age, who were operated for isolated VSD and were on regular follow-up in our institute.

\section{Exclusion Criterion}

1) Patients with concomitant procedures except those who underwent patent foramen ovale closure or PDA ligation.

2) Syndromic patients.

3) Patients with multiple VSDs.

4) Patients who had undergone previous pulmonary artery banding.

Out of 120 patients, only 84 patients were identified as satisfying these criteria. Preoperative, perioperative and postoperative data of these patients was collected from the echocardiography reports, perfusion reports, clinic, inpatient and operative notes. All these patients who met the inclusion criteria were analyzed in follow-up.

\section{Surgical Technique}

All patients underwent median sternotomy. Cardiopulmonary bypass with moderate hypothermia was used in all patients. Del Nido cold crystalloid cardioplegia was used for myocardial preservation, supplemented with topical ice slush. Three surgeons operated during this period. Dacron (with interrupted polypropylene sutures) was the patch material used in all cases. Ductus arteriosus was dissected and ligated, if present before VSD closure.

\section{Statistical Analysis}

Statistical analyses were performed as follows: means, medians, standard deviations, and ranges were used to describe continuous variables. Frequencies and percentages were used for categorical data.

\section{Definitions}

Early mortality was defined as death within one month period of surgery while death after one month was defined as late mortality. Other characteristics like size of defect, degree of valvular regurgitation and degree of residual VSD, demonstrated on postoperative echocardiograms, were based on the judgment of the interpreting paediatric cardiologist. A clinical diagnosis of failure to thrive was made for children whose weight fell below the fifth percentile for their age or who weighed less than $80 \%$ of their ideal weight based on the standard growth charts. During cardiography, right ventricular and pulmonary artery pressures were estimated using the tricuspid regurgitation jet velocity. Residual VSDs were defined as small if they were less than $2 \mathrm{~mm}$ in size and were pressure restrictive.

\section{Results}

\section{Patient Demograhics}

The median age at repair was 8 months (range, 2 months to 11.5 months) and weight was $5 \mathrm{~kg}$ (range, 2.5 to $9 \mathrm{~kg}$ ). No patient with genetic abnormality was included in our study. 81 patients (95\%) were admitted for surgery electively from outpatient clinic while 3 patients were transferred from paediatric cardiology department for urgent surgery. 74 patients (88\%) had a perimembranous VSD, while 2 had supracristal $(2.3 \%), 3$ had inlet $(3.5 \%)$, and 5 had muscular $(5.9 \%)$ defects. 13 patients $(15.7 \%)$ underwent concomitant repair of an atrial septal defect or patent foramen ovale closure, and 9 patients $(10.71 \%)$ had a patent ductus arteriosus ligation. 


\section{Indications for Surgery}

Indications for operative intervention were taken from the referring cardiologist's or the surgeon's preoperative note and are summarize in table 1.

Table 1 Indications for Surgery Based on Referring Cardiologist's or Surgeon's Preoperative Note

\begin{tabular}{|l|c|c|}
\hline Indication & $\begin{array}{c}\text { Number of } \\
\text { patients }\end{array}$ & $\%$ \\
\hline Recurrent pneumonias & 48 & 57.14 \\
\hline Poor weight gain & 36 & 42.85 \\
\hline Pulmonary hypertension & 55 & 65.47 \\
\hline Failure to thrive & 42 & 50.00 \\
\hline Congestive heart failure & 32 & 38.09 \\
\hline
\end{tabular}

Most of patients have two or more of these indications.

Echocardiographic findings on preoperative studies are summarized in Table 2. Of the patients with left atrial enlargement, 16 were characterized as mild, 3 as moderate, and 1 as severe. Of the patients with left ventricular enlargement, 4 were characterized as mild, and 1 as moderate. None of the patients underwent preoperative cardiac catheterization. Of the patients with pulmonary arterial hypertension, 25 were characterised as mild, 8 as moderate, and 22 as severe.

Table 2 Findings on Preoperative Echocardiography

\begin{tabular}{|l|c|c|}
\hline Finding & $\begin{array}{c}\text { Number of } \\
\text { patients }\end{array}$ & $\%$ \\
\hline Left atrial enlargement & 20 & 23.51 \\
\hline Left ventricular enlargement & 5 & 5.95 \\
\hline $\begin{array}{l}\text { Pulmonary arterial } \\
\text { hypertension }\end{array}$ & 55 & 65.47 \\
\hline Large non restrictive VSD & 60 & 73.15 \\
\hline
\end{tabular}

\section{Surgical Approach and Operative Data}

All patients were approached through median sternotomy. After pericardiotomy, aorto bicaval cannulation done. PDA dissected and ligated if present. Heart arrested with del Nido cold blood cardioplegia and adenosine, supplemented with topical ice slush. Of the perimembranous VSDs, all were closed from a transatrial approach. Of the supracristal VSDs, 1 from a transatrial approach, and 1 from a combined transatrial and transpulmonary approach. All inlet and muscular
VSDs, including apical VSDs, were closed transatrially through the tricuspid valve. 82 patients underwent Dacron patch repair of their VSD while in two patients VSD was closed primarily using interrupted sutures. None of our patients had intraoperative transesophageal echocardiography.

Median operative time was 206 minutes (range, 120 to 456 minutes). Median cardiopulmonary bypass time was 117 minutes (range, 60 to 235 minutes). Median cross-clamp time was 63 minutes (range, 35 to 138 minutes). Moderate hypothermia was used during cardiopulmonary bypass (mean temperature, $28^{\circ} \pm 2^{\circ} \mathrm{C}$ ). All patients $(100 \%)$ received blood products, either packed red blood cells, platelets, or fresh-frozen plasma, intraoperatively. All the operative characteristics are summarised in table 3.

Table 3 Operative data and early hospital course

\begin{tabular}{|l|c|c|}
\hline Trans atrial approach & 83 patients & $98.80 \%$ \\
\hline $\begin{array}{l}\text { Transatrial patient } \\
\text { transpulmonary } \\
\text { approach }\end{array}$ & $1.20 \%$ \\
\hline Dacron patch repair & 82 patients & $97.61 \%$ \\
\hline Direct suture closure & 2 patients & $2.39 \%$ \\
\hline Operative time & $\begin{array}{c}\text { Mean, 206 } \\
\text { minutes }\end{array}$ & $\begin{array}{c}\text { Range, 120 to } \\
456 \text { minutes }\end{array}$ \\
\hline $\begin{array}{l}\text { Cardio pulmonary } \\
\text { bypass time }\end{array}$ & $\begin{array}{c}\text { Mean, 117 } \\
\text { minutes }\end{array}$ & $\begin{array}{c}\text { Range, 60 to } \\
235 \text { minutes }\end{array}$ \\
\hline Cross clamp time & $\begin{array}{c}\text { Mean, 63 } \\
\text { minutes }\end{array}$ & $\begin{array}{c}\text { Range, 35 to } \\
138 \text { minutes }\end{array}$ \\
\hline Extubation time & $\begin{array}{c}\text { Mean, 12 } \\
\text { hours }\end{array}$ & $\begin{array}{c}\text { Range, 6 to 30 } \\
\text { hours }\end{array}$ \\
\hline ICU stay operative & Mean, 3 days & $\begin{array}{c}\text { Range, 2 to } 15 \\
\text { days }\end{array}$ \\
\hline $\begin{array}{l}\text { Post heans } \\
\text { hospital stay }\end{array}$ & $\begin{array}{c}\text { Range, 4 to 26 } \\
\text { days }\end{array}$ \\
\hline
\end{tabular}

\section{Hospital Course}

Mean extubation time was 12 hours (range, 6 hours to 30 hours), mean ICU stay was 3 days (range, 2 to 15 days) and mean postoperative hospital length of stay was 5 days (range, 4 to 15 days). 1 reoperation $(1.15 \%)$ was performed for permanent pacemaker implantation. 1 patient $(1.15 \%)$ had postoperative bleeding requiring reoperation. 1 patient $(1.15 \%)$ was reintubated after three hours of extubation. 3 patients $(3.5 \%)$ needed pleural drain placement in ICU. 1 patient 
developed urethral injury related hematuria in ICU, which resolved on its own in 24 hours. 20 patients $(23.2 \%)$ received packed red blood cells or other blood products, postoperatively. There were no mediastinal or deep sternal wound infections. There were no neurologic complications or seizures in early postoperative period. Complications have been summarised in table 4.

Table 4 Post Operative Complications

\begin{tabular}{|l|c|c|}
\hline Complication & No of patient & Percentage \\
\hline Reintubation & 1 & 1.15 \\
\hline Reoperation & 2 & 2.30 \\
\hline Hemo/pneumothorax & 3 & 3.45 \\
\hline Hematuria & 1 & 1.15 \\
\hline Wound infection & 0 & 0 \\
\hline $\begin{array}{l}\text { Neurological } \\
\text { complications valvular }\end{array}$ & 0 & 0 \\
\hline $\begin{array}{l}\text { New } \\
\text { insufficiency }\end{array}$ & 1 & 0 \\
\hline Complete heart block & 2 & 1.15 \\
\hline Early deaths & 1 & 1.15 \\
\hline Late death & & \\
\hline
\end{tabular}

\section{Mortality}

Two early deaths $(2.3 \%)$ occurred in our series (see table 4). 1 early mortality occurred in a 4 month infant with large perimembranous VSD and severe Pulmonary artery hypertension. He developed complete heart block post operatively, permanent pacemaker implantation was done on $26^{\text {th }}$ post operative day, the patient expired on $28^{\text {th }}$ post operative day in ICU of sepsis and ARDS. Another early death in our series is of a 6 month old infant with large perimembranous VSD with severe Pulmonary artery hypertension. Patient couldn't be weaned off cardiopulmonary bypass and was shifted to ICU on venoarterial ECMO support. Patient expired on $7^{\text {th }}$ day post operative day of sepsis and disseminated intravascular coagulation (DIC).

\section{Follow-Up}

Median follow-up period of our patients was 3 years (range, 1 year to 5 years). On follow-up electrocardiograms, none of our patients exhibited complete heart block. At follow-up echocardiograms, 78 patients $(93 \%)$ had no residual VSD. Of the remaining 3 patients, the residual VSDs were characterized as small, all of which closed spontaneously in over follow up period. 79 patients $(94.2 \%)$ had normal left ventricular function on follow up echocardiogram, 1 patient $(1.15 \%)$ had mildly depressed left ventricular function on $4^{\text {th }}$ post operative day while none had severely depressed left ventricular function. No patient had new onset aortic or tricuspid regurgitation greater than trivial postoperatively. 50 patients were discharged on medication for pulmonary hypertension. Pulmonary hypertension regressed over median time of 2 months (range, few hours after surgery to 5 months). One pulmonary artery hypertension (PAH) related death occurred in follow up period, 5 months after surgery in a 7 month old infant with preoperative diagnosis of large VSD with severe PAH, whose PAH didn't regressed even after surgery.

\section{Discussion}

There has been significant improvements in results for surgical repair of ventricular septal defects since the first series reported by Lillehei and colleagues in 1955 and are attributed to advancements in surgical technique and intraoperative and perioperative management ${ }^{2}$. In 2004 Roos et al in a study cited excellent longterm survival and clinical outcomes for these patients, $92 \%$ of patients were in New York Heart Association class I more than 20 years after repair $^{5}$. Long-term results are similarly positive for infants who undergo repair of VSD, with Meijboom et al reporting all survivors growing normally with a good quality of life after more than 10 years after surgery ${ }^{6}$.

In terms of overall outcomes, our in-hospital mortality of $3.4 \%$ was higher than mortality rates for VSD repair in developed countries. Mortality has been reduced to between $0.5 \%$ and $1.7 \%$ in Western healthcare systems ${ }^{3,7}$. Our mortality rate however, is lower than the mortality rates shown by Vaidyanathan et al for the same procedure ${ }^{8}$.

Similarly, there has been a significant reduction in perioperative morbidity since last two decades, 
from $29 \%$ to $15 \%$ in children who underwent VSD repairs ${ }^{9}$. This is comparable to the post operative morbidity seen in this study, but different in that cardiac dysrhythmia is the most common complication in developed countries ${ }^{9}$, while chest complications were most common in our study.

In our study, most adverse complications were redo surgery $(1.15 \%)$ and complete heart block leading to permanent pacemaker implantation $(1.15 \%)$. These adverse events are however lower than reported by Anderson etal who reported $2.1 \%$ rate for permanent pacemaker, and $4.9 \%$ for re-do surgery 9 . Another study reported a reoperation rate of $2.8 \%$ after surgical closure of an isolated single $\mathrm{VSD}^{10}$.

Vaidhyanathan et al in 2002, demonstrated that operative weight was not associated with the length of hospital stay, but that younger age and preoperative pneumonia required longer postoperative care $^{8}$. Another study by Kouchooukos et al in 2003 concluded that young age, patient size etc, which have been predictive of hospital mortality in the past are no longer risk factors ${ }^{11}$.

$65 \%$ of our patients had PAH, which was significantly associated with adverse outcome, as all our mortalities were in patients with severe PAH. Several studies have shown the association between PAH and higher mortality and morbidity in patients undergoing VSD repair. Aldemir etal (2013) strongly adviced early surgical repair of VSD in patients having severe PAH for more favourable results ${ }^{11}$.

\section{Limitations}

The limitations of this study are primarily defined by the limitations of all retrospective chart studies. In a prospective study more information could be assessed and the length of follow-up could be more consistent. Secondary this was a single institutional experience so our findings may not be applicable to other centers.

\section{Conclusion}

Surgical closure of VSD in infancy is associated with low mortality and extremely low incidence of adverse events. Surgery should not be postponed just for gaining weight or increasing age as early surgical correction of VSD is the only safeguard against this left to right shunt with all its accompanying morbidity and mortality.

\section{Disclosure Statement and conflict of interest:}

The authors declare that they have no disclosure and there is no conflict of interest.

\section{Bibliography}

1. Hoffman JI, Kaplan S, Liberthson RR. Prevalence of congenital heart disease. Am Heart J. 2004;147:425-39.

2. Mavroudis C, Backer CL, Jacobs JP. Ventricular septal defect. In: Mavroudis C, Backer CL, eds. Pediatric cardiac surgery, 3rd ed. Philadelphia: Mosby, 2003:298 320.

3. Anderson BR, Stevens KN, Nicolson SC et al (2013) Contemporary outcomes of surgical ventricular septal defect closure. J Thorac Cardiovasc Surg 145(3):641-647

4. Kogon B, Butler H, Kirshbom P, Kanter K, McConnell M (2008) Closure of symptomatic ventricular septal defects: how early is too early? Pediatr Cardiol 29(1):36-39

5. Roos-Hesselink JW, Jeijboom FJ, Spitaels SE, et al. Outcome of patients after surgical closure of ventricular septal defect at young age: longitudinal follow-up of 22-34 years. Eur Heart J 2004;25:105762.

6. Meijboom F, Szatmari A, Utens E, et al. Long-term follow-up after surgical closure of ventricular septal defect in infancy and childhood. J Am Coll Cardiol 1994;24:1358-64.

7. Scully BB, Morales DL, Zafar F, McKenzie ED, Fraser CD Jr, et al. (2010)Current expectations for surgical 
repair of isolated ventricular septal defects. Ann Thorac Surg 89: 544-549.

8. Vaidyanathan B, Roth SJ, Rao SG, Gauvreau K, Shivaprakasha K, et al. (2002) Outcome of ventricular septal defect repair in a developing country. $\mathrm{J}$ Pediatr 140: 736-741

9. Nygren A, Sunnegårdh J, Berggren $\mathrm{H}$ (2000) Preoperative evaluation and surgery in isolated ventricular septal defects: a 21 year perspective. Heart 83: 198-204.

10. Scully BB, Morales DL, Zafar F, McKenzie ED, Fraser CD Jr, et al. (2010) Current expectations for surgical repair of isolated ventricular septal defects. Ann Thorac Surg 89: 544-549.

11. Koukchoukos NT, Blackston EH, Doty DB et al. Ventricular septal defect, in Kirklin/Barrat-Boyes cardiac surgery, 3rd edn. Churchill Livingstone, Philadelphia. 2003.

12. Aydemir NA, Harmandar B, Karaci AR et al. Results for surgical closure of isolated ventricular septal defects in patients under one year of age. J Card Surg. 2013;28(2):174-9. 